\title{
Misplaced PPIUCD, Uncommon Complication in Common Procedure
}

\author{
Uttara Shelke', Deepti Shrivastava² ${ }^{2}$ Harsha Shekhawat ${ }^{3}$, Abhishek Kothule ${ }^{4}$
}

\begin{abstract}
${ }^{1}$ Department of Obstetrics and Gynaecology, Jawaharlal Nehru Medical College, Sawangi, Wardha, Maharashtra, India. 2Department of Obstetrics and Gynaecology, Jawaharlal Nehru Medical College, Sawangi, Wardha, Maharashtra, India. ${ }^{3}$ Department of Obstetrics and Gynaecology, Jawaharlal Nehru Medical College, Sawangi, Wardha, Maharashtra, India. ${ }^{4}$ Department of Obstetrics and Gynaecology, Jawaharlal Nehru Medical College, Sawangi, Wardha, Maharashtra, India.
\end{abstract}

\section{INTRODUCTION}

An ideal contraceptive is the one having features like being safe, effective, acceptable, inexpensive, reversible, simple to administer, independent of coitus, long lasting and requires little or no medical supervision.(1) Couple protection rate (CPR) of India currently is $54.8 \%$ among the eligible couples in the age group of $15-44$ years.(2) In view of low CPR, National Health Mission has intensified the PPIUCD program. According to India's Vision FP 2020', emphasis is laid on training of more nurses to deliver the service in a 24 hour mode to the women opting for the method. In addition to this, women are highly motivated and most receptive towards family planning during the postpartum period but dilemma and conflict begins if any complication is met with, as in this case scenario.

Intra-Uterine Copper Device (IUCD) is a safe, reversible and a cost-effective longterm contraceptive method. According to the WHO Eligibility criteria, post-placental and immediate Postpartum Intra uterine Copper Device insertion is done immediately after delivery of the placenta, within ten minutes to 48 hours respectively.(3) In a study, it was shown that IUCD insertion rate was as high as $95 \%$ in patients willing for immediate postpartum insertion, as compared this rate declined to only $45 \%$ in those consenting for a later insertion. ${ }^{(4)}$

Although this method provides effective contraception, it is associated with complications, with uterine perforation being the rare but potentially devastating complication that can cause severe morbidity.(5) There are many incidences reported of uterine perforation due to postpartum IUCD insertion after interval IUCD technique, but none reported after post-placental or immediate postpartum IUCD insertion. We present a case report of uterine perforation after post-placental IUCD insertion.

\section{PRESENTATION OF CASE}

A 23-year-old P1L1 came to our hospital with complaints of discomfort in the lower abdomen and wished to remove the IUCD. She had a normal delivery 4 months back with history of post-placental $\mathrm{Cu}$-T insertion at the time of delivery at Primary Health Care Centre. She was breast feeding the baby. She wished to get the device removed with fear of ill health due to the IUCD, as it was inserted immediately after the delivery, informed to her and consent was obtained after the procedure. On per speculum examination, $\mathrm{Cu}$ - $\mathrm{T}$ thread was not visible, the cervix was found to be normal. On per vaginal examination, uterus was normal size, soft and fornices were free.

\author{
Corresponding Author: \\ Dr. Uttara Shelke, \\ F27, Shalinata Hostel, \\ JNMC, Sawangi, Wardha, \\ Maharashtra, India. \\ E-mail: uttarashelke03@gmail.com
}

DOI: $10.14260 / j e m d s / 2020 / 520$

How to Cite This Article:

Shelke U, Shrivastava D, Shekhawat $H$, et al. Misplaced PPIUCD, uncommon complication in common procedure. $J$ Evolution Med Dent. Sci 2020;9(33):23972399, DOI: 10.14260/jemds/2020/520

Submission 13-05-2020,

Peer Review 08-07-2020,

Acceptance 15-07-2020,

Published 17-08-2020.

Copyright (C) 2020 JEMDS. This is an open access article distributed under Creative Commons Attribution License [Attribution 4.0 International (CC BY 4.0)] 
X-ray straight lower abdomen was done promptly with uterine sound in place within the uterine cavity. The x-ray showed the $\mathrm{Cu}-\mathrm{T}$ in the pelvis lateral to the uterine sound, however its intrauterine or extrauterine location could not be determined as seen in fig 1 . Hence decision of fluoroscopic HSG was taken, as this facility is available round the clock in our hospital and the $\mathrm{Cu}$-T was visualized lying horizontally in the pelvis with no abnormal spillage.

Patient was advised diagnostic and therapeutic hysterolaparoscopy for further management, consent for laparotomy was also taken. On hysteroscopic examination, the cervical canal was normal, $\mathrm{Cu}-\mathrm{T}$ or its threads were not visualized anywhere in the uterine cavity or the endocervical canal. The uterine cavity appeared normal, with no obvious evidence of indentation in the cavity and the endometrium seemed intact, cornual openings of both fallopian tubes visualized were normal.

On laparoscopic examination, no signs of any hemoperitoneum, faecal peritonitis or bowel perforation seen. No evidence of any uterine perforation seen, the serosa was intact. On further examination the $\mathrm{Cu}$-T was seen embedded in the omentum, horizontally as seen in fig 2 . Minimal free fluid was seen in the pelvic cavity. The $\mathrm{Cu}-\mathrm{T}$ was removed intact and haemostasis achieved. Post-operative recovery was uneventful.
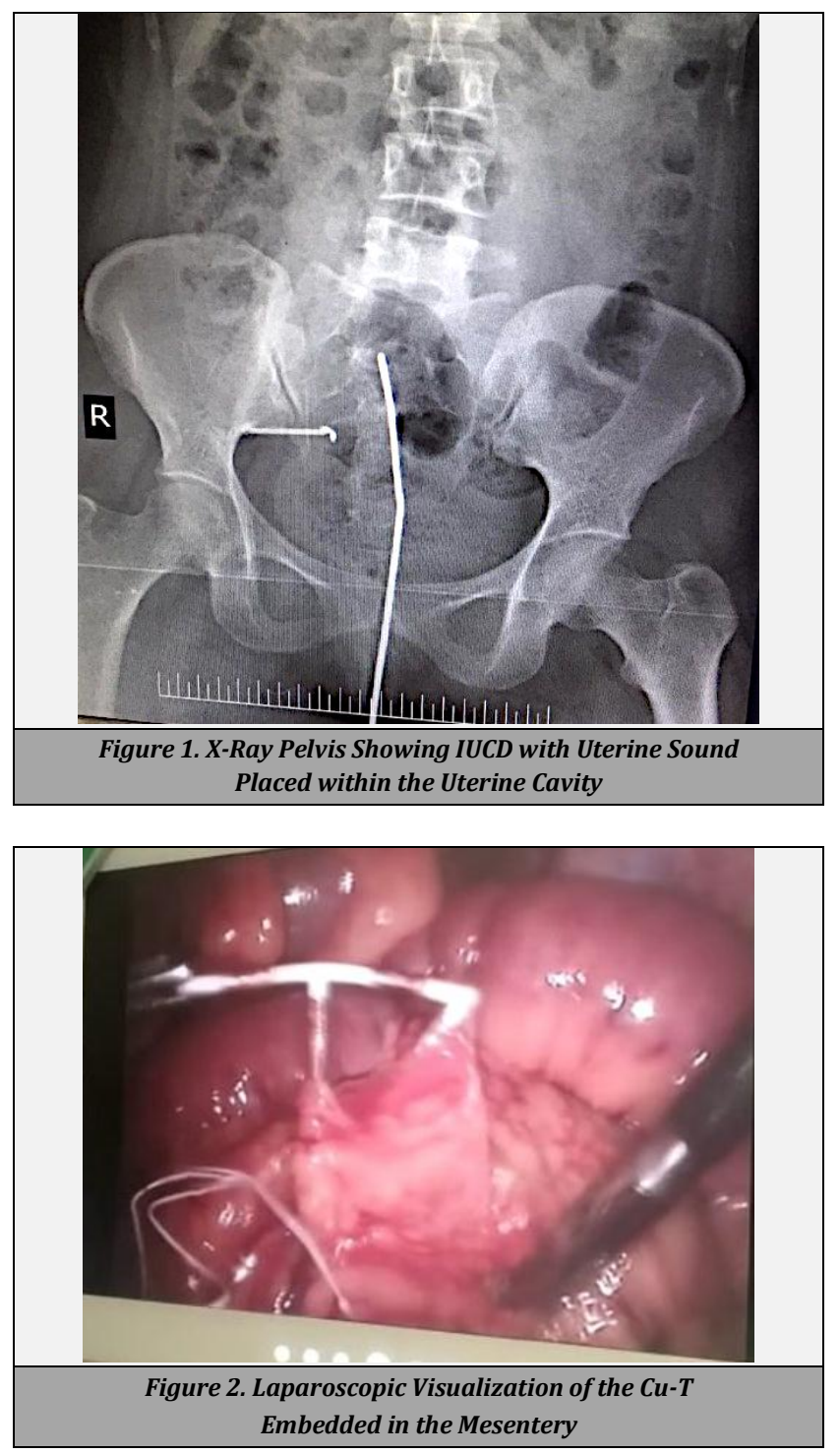

\section{DISCUSSION}

PPIUCD has many advantages such as reversible method, no interference with breast feeding, coitus independent, and long term contraceptive with negligible systemic side effects fulfilling the criteria of LARC if inserted with proper consent and willingness of the patient. The side effects include abdominal pain, menstrual irregularities, expulsion, pelvic inflammatory disease and uterine perforation. Perforation of the uterus is one of the most serious complication associated with the use of an IUCD. Perforation may be complete or partial.(6) The general incidence of uterine perforation for all types of IUCD has been estimated at $0.87 / 1000 .(7)$ A study of 3029 cases of postpartum intrauterine contraceptive device in Paraguay from 2000 to 2009 showed a perforation rate of $0.0 \%$ and spontaneous expulsion rate of $1.4 \%$.(8) However, perforation with PPIUCD was not reported till recent times.

Majority of the times the perforation is not recognized at the time of insertion and such asymptomatic patients may not be identified until many years later. Ozgu Aydogdu et al reported a case of incidental finding of a transmigrated IUCD in the abdomen after 30 years of its placement.(9) Our case too, presented asymptomatically and with misplaced IUCD. The transmigrated IUCD maybe a cause for infection, intestinal obstruction, intestinal perforation and formation of adhesion. This can involve several internal organs such as bowel and bladder leading to perforation or associated complications.

In our case the IUCD migrated posteriorly and got embedded in the mesentery fortunately not perforating the bowel. IUCD should be examined periodically with proper patient education at the time of insertion.(10) Our patient did not go for follow-up, until she was convinced under family pressure that its continuous use my cause her ill health. Periodic self-examination for the thread is advocated and is useful in early detection of any misplaced IUCD. An ultrasound to confirm proper position after insertion is recommended but is not a standard practice and not feasible. A plain x-ray of the pelvis is usually the initial investigation of choice to detect the location of the IUCD in the pelvis.

It is important to treat patients having migrated IUCDs for any psychosomatic symptoms.(10) The definitive treatment of a migrated IUCD is surgical although Markovitch and colleagues believe that asymptomatic patients may be managed conservatively under some circumstances.(7) Removal of the intra-abdominal IUCD laparoscopically should be the preferred choice of surgical management unless contraindicated.(10) If laparoscopy is contraindicated laparotomy should be performed.

\section{CONCLUSIONS}

This report warrants physicians to be careful of asymptomatic patients following IUCD insertion. Periodic follow up is mandatory which is possible only with prior information and willingness of the patient. Conflict may arise with diagnosis of complication especially in a rural set up with unmotivated patients. It is a common finding of not feeling the $\mathrm{Cu}$-T threads with very uncommon and disastrous complication of uterine perforation. Laparoscopic removal of intra-abdominal IUCD is 
the preferred management based on the patient characteristics and presentation.

Financial or Other Competing Interests: None.

\section{REFERENCES}

[1] Park K. Demography and family planning. In: Park K. Park's textbook of preventive and social medicine. 24th edn. Jabalpur: M/S Banarsidas Bhanot 2017:525-52.

[2] Gummaraj NV, Menzil M, Kurre B, et al. Contraceptive practices among the eligible couples from a rural and an urban area of Karnataka. National Journal of Community Medicine 2018;9(7):524-8.

[3] WHO. Family planning: a global handbook for providers: evidence-based guidance developed through worldwide collaboration. Geneva: World Health Organization 2018.

[4] Echeverry G. Family planning in the immediate postpartum period. Studies in Family Planning 1973;4(2):33-5.
[5] Tunçay YA, Tunçay E, Güzin $K$, et al. Transuterine migration as a complication of intrauterine contraceptive devices: six case reports. Eur J Contracept Reprod Health Care 2004;9(3):194-200.

[6] Heinberg EM, McCoy TW, Pasic R, et al. The perforated intrauterine device: endoscopic retrieval. JSLS 2008;12(1):97-100.

[7] Markovitch O, Klein Z, Gidoni Y, et al. Extrauterine mislocated IUD: is surgical removal mandatory? Contraception 2002;66(2):105-8.

[8] Yellayi ASSR, Aruna S, Bai KS. A case report of a perforated postpartum intrauterine contraceptive device and review of literature. International Journal of Scientific Study 2015;3(2):248-50.

[9] Aydogdu 0, Pulat H. Asymptomatic far-migration of an intrauterine device into the abdominal cavity: a rare entity. Can Urol Assoc J 2012;6(3):E134-6.

[10] Mülayim B, Mülayim S, Celik NY. A lost intrauterine device. Guess where we found it and how it happened? Eur J Contracept Reprod Health Care 2006;11(1):47-9. 